adhering strictly to the diet and $2.6 \mathrm{lb} .(1.18 \mathrm{~kg}$.) in those deviating from it.

The five meals a day diet was acceptable to many patients with " refractory obesity," but the results were satisfactory only in those who adhered strictly to the diet.

We wish to thank Miss E. M. Wilson for preparing the diets and for assistance with the study.
REFERENCES

Duncan, L. J. P., Rose, K., and Meiklejohn, A. P. (1960). Lancet, 1, 1262.

Fábry, P., Fodor, J., Heil, Z., Braun, T., and Zvolánková, K. (1964). Ibid., 2, 614 .

Gordon, E. S., Goldberg, M., and Chosy, G. J. (1963). F. Amer. med. Ass., 186, 50.

Hollifield, G., and Parson, W. (1962). f. clin. Invest., 41, 245.

Seaton, D. A., and Duncan, L. J. P. (1963). Brit. med. f., 2, 219. - (1964). Lancet, 2, 612.

- Rose, K., and Scott, A. M. (1961). Brit. med. F., 1, 1009. Rose, K., and Duncan, L. J. P. (1964a). Practitioner, 193, 698

- - (1964b). Scot. med. f., 9, 482 .

\title{
Recurrent Infection of the Urinary Tract: Reinfection or Recrudescence?
}

\author{
JAMES MCGEACHIE,* M.D., M.C.PATH.
}

\author{
Brit. med. F., 1966, 1, 952-954
}

Though infections of the urinary tract may respond to modern antibacterial therapy, the frequency of recurrent urinary infections has altered little from the pre-antibiotic era (Rhoads, Billings, and O'Conor, 1952). The frequency of recurrence depends to a great extent on the pathogenesis of the infection; obviously where some obstructive factor is present the probability of recurrence is high without the necessary correction of the underlying defect. Even where no associated lesion of the urinary tract is apparent the rate of recurrence is still frequent (Garrod, Shooter, and Curwen, 1954 ; Jackson, Poirier, and Grieble, 1957). Indeed it is probably true to say that, though the bacteriological cure of urinary infection has been accelerated with the use of modern therapy, the recurrence rate following short-term therapy is no lower than formerly. The problem with recurrence may be expressed by the question, Is recurrence a recrudescence of an inadequately eradicated infection or is it an infection by a new organism? Where the recurrence is associated with a different species, assuming that this species was absent from the initial infection, then little doubt can exist that this is a reinfection. However, where the species isolated is the same in both episodes then the differentiation requires further classification other than biochemical. It was hoped that by employing serological and colicine typing methods some clarification of the problem might be obtained.

\section{Material and Methods}

Forty-nine patients attending the medical renal clinic or in-patient medical wards of the Glasgow Royal Infirmary were investigated for 108 recurrent infections with Escherichia coli over four years. Each patient had an established infection with $E$. coli which responded to treatment and was followed by a further infection with $E$. coli. Infection was accepted by the presence of more than 100,000 organisms per ml. of urine, demonstrated by the quantitative bacterial-count technique described previously (McGeachie and Kennedy, 1963). Where possible two or more pretreatment, mid-stream specimens of urine were obtained to confirm the presence of significant bacteriuria. Of the 49 patients with recurrent infections 37 females and the sole male had no demonstrable abnormality of the urinary tract. The remaining 11 , all females, had the following abnormalities: glomerulonephritis (3), acute tubular necrosis (3), nephrosis (1), renal calculus (1), KimmelstielWilson kidneys (1), duplication of the renal pelvis (1), and

* Lecturer, University Department of Bacteriology, Glasgow Royal Infirmary. disseminated sclerosis (1). These 11 patients had 39 recurrent episodes.

The patients were prescribed a course of appropriate antibacterial therapy, which varied from 5 to 10 days. The proof of eradication of infection was taken by the continued sterility of urine, associated with the absence of symptoms and pyuria, during treatment, for at least two days after the cessation of therapy, and again at 10 days or longer. Indication of recurrence was considered when there was a bacterial count of more than 100,000 organisms per $\mathrm{ml}$. of urine following the period of sterile urine cultures. Further mid-stream specimens were obtained at the medical renal clinic at two weeks, at one month, then at monthly intervals for six months to one year, then at three-monthly intervals for a further year, and, should no further episodes of infection occur, at six-monthly intervals for the next two years.

It is not intended to discuss the therapeutic management of urinary infection in detail, however; it will be sufficient to state that the short-term therapy was used only for the comparison of antibacterial substances, and as a rule long-term treatment was the method of choice.

Methods of Investigation.-The colonies of $E$. coli were isolated on the diagnostic culture plates and subcultured on to nutrient agar slopes, incubated for 18 hours at $37^{\circ} \mathrm{C}$., allowed to cool to room temperature, and stored at $4^{\circ} \mathrm{C}$. If it was not possible to investigate the subcultures within a few days they were lyophilized. The cultures were typed by . serological methods and by colicine production and colicine-sensitivity methods.

Serological Grouping.-The preparation and methods for serological grouping have been described in detail elsewhere (McGeachie, 1965a). The antisera used were prepared against 12 specific O groups-O1, O2, O4, O5, O6, O7, O8, O9, O11, $\mathrm{O} 18$, O39, and $\mathrm{O} 75-$ in which the majority of pathogenic strains have been found to occur (Vahine, 1945 ; Kauffman, 1947 ; Ujváry, 1958 ; Rantz, 1962 ; McGeachie, 1965a).

Colicine Typing.-Colicines are specific antibiotic substances produced by the Enterobacteriaceae ; they are bactericidal to other strains which have the appropriate receptor point on their surface. The property of producing colicine is a highly stable hereditary characteristic of bacteria which is governed by colicinogenic factors (Fredericq, 1965). Thus the typing of a strain of $E$. coli may be performed by using its colicine production pattern and its colicine sensitivity pattern as markers. The methods of colicine typing employed in this study have been described in detail elsewhere (McGeachie, 1965b). A freezethaw method of colicine extraction from the culture was used 
and the colicine production pattern of the isolate was tested by means of 15 indicator strains-14 shigellae and $E$. coli Row. The colicine-sensitivity pattern was tested with eight known colicine extracts.

\section{Results}

Reproducibility of Pretreatment Isolates.-Sixty-five pretreatment specimens were obtained from 23 patients, $63(97 \%)$ agreed with colicine production and for colicine sensitivity, 62 (95.4\%) agreed serologically with their companion specimens. Two of the specimens were serologically non-typable owing to roughness; if one excludes these from comparison the serological agreement was $98.4 \%$.

Recurrent Infections.-Of 108 recurrences 17 (15.8\%) had the same strain of $E$. coli and $91(84.2 \%)$ had a strain of $E$. coli which differed from the infecting strain previously isolated (Table I).

TABLE I.-Incidence of Recurrent Infections at the Various Time

\begin{tabular}{c|c|c|c}
\multicolumn{2}{c}{ Intervals } \\
$\begin{array}{c}\text { Months Since } \\
\text { Previous Infection }\end{array}$ & $\begin{array}{c}\text { Change of } \\
\text { Strain }\end{array}$ & $\begin{array}{c}\text { Strain } \\
\text { Identical }\end{array}$ & Total \\
\hline$\leqslant 1$ & 25 & 5 & 30 \\
$1-3$ & 35 & 11 & 46 \\
$3-6$ & 21 & - & 21 \\
$6-12$ & 5 & 5 \\
$>12$ & 5 & 17 & 5 \\
\hline Total & 91 & 108 \\
\hline
\end{tabular}

Distribution of Time Interval in Recurrences.-This is shown in Table I. Of the 30 patients who had recurrences within one month of the previous infection 15 had them in two to three weeks, and 13 of these incidents were due to a different strain of $E$. coli, the other two being due to similar strains as shown by the typing markers.

Changes in the Typing Markers of the Recurrent Isolates.Fifty-one $(56 \%)$ of the variations in the isolates were due to a change in the colicine production pattern, $61(67 \%)$ to a change in the serological group, and $65(71.4 \%)$ to a change in the colicine sensitivity pattern (Table II). These changes are more specifically considered in Table III. The commonest difference was shown by a change in all the markers: this occurred in 19 $(21 \%)$ of the 91 incidents. A change in both the colicine sensitivity and the serological group occurred in $18(20 \%)$

TABLE II.-Variations in Typing Markers in the Recurrent Infections

\begin{tabular}{|c|c|c|c|c|}
\hline \multirow{2}{*}{$\begin{array}{c}\text { Months Since } \\
\text { Previous } \\
\text { Infection }\end{array}$} & \multicolumn{3}{|c|}{ Change of Marker from Previous Specimen } & \multirow{2}{*}{$\begin{array}{c}\text { Total } \\
\text { Incidents }\end{array}$} \\
\hline & Production & Sensitivity & Serology & \\
\hline $\begin{array}{l}\leqslant 1 \\
1-3 \\
3-6 \\
6-12 \\
>12\end{array}$ & $\begin{array}{r}12 \\
23 \\
10 \\
4 \\
2\end{array}$ & $\begin{array}{r}18 \\
26 \\
14 \\
3 \\
4\end{array}$ & $\begin{array}{r}15 \\
19 \\
19 \\
4 \\
4\end{array}$ & $\begin{array}{r}25 \\
35 \\
21 \\
5 \\
5\end{array}$ \\
\hline Total & 51 & 65 & 61 & 91 \\
\hline
\end{tabular}

TABLE III.-Variations in Markers of the Isolates from the Recurrent Infections

\begin{tabular}{|c|c|c|c|c|c|c|c|c|}
\hline \multirow{2}{*}{$\begin{array}{l}\text { Months } \\
\text { Since } \\
\text { Previous } \\
\text { Infection }\end{array}$} & \multicolumn{7}{|c|}{ Difference from Previous Isolate } & \multirow{2}{*}{ Total } \\
\hline & $\mathbf{P}$ & $\mathbf{S}$ & Ser & $\mathbf{P} / \mathbf{S}$ & $\mathbf{P} /$ Ser & S/Ser & $\mathrm{P} / \mathrm{S} / \mathrm{Ser}$ & \\
\hline $\begin{array}{l}\leqslant 1 \\
1-3 \\
3-6 \\
6-12 \\
>12\end{array}$ & $\begin{array}{l}3 \\
1 \\
2 \\
1\end{array}$ & $\begin{array}{l}4 \\
5 \\
5\end{array}$ & $\begin{array}{l}2 \\
3 \\
2 \\
1\end{array}$ & $\begin{array}{r}3 \\
10 \\
1\end{array}$ & $\begin{array}{l}2 \\
5 \\
3 \\
1\end{array}$ & $\begin{array}{l}7 \\
4 \\
4 \\
3\end{array}$ & $\begin{array}{l}4 \\
7 \\
4 \\
3 \\
1\end{array}$ & $\begin{array}{r}25 \\
35 \\
21 \\
5 \\
5\end{array}$ \\
\hline Total & 7 & 14 & 8 & 14 & 11 & 18 & 19 & 91 \\
\hline
\end{tabular}

\footnotetext{
P $\quad=$ Colicine production only.

P
Ser $\quad=$ Colicine sensitivity only.

Ser $\quad$ a Serology only.
P/S $=$ Both colicine prot

P/S = Both colicine production and sensitivity.

P/Ser = Both colicine production and serology.

S/Ser $=$ Both colicine sensitivity and serology.
}

$\mathrm{P} / \mathrm{S} / \mathrm{Ser}=$ Colicine production, sensitivity, and serology. incidents. In 14 incidents both the colicine production and sensitivity changed, and in a similar number only the colicine sensitivity changed. The remaining incidents showed changes in colicine production and serology (11), serology only (8), and colicine production only (7).

Abnormalities of Urinary Tract and Recurrences.-Eleven patients with abnormalities of the urinary tract had 39 recurrences; there was a change in the strains in 37 . The patient with renal calculus had five recurrences, from only one of which was isolated an identical strain to the previous one, five weeks before. The patient with duplication of the renal pelvis had a recurrence with a strain identical to the previous one, six weeks before. The difference in frequency of the change marker between the patients with abnormalities and those without was not highly significant $\left(\chi^{2}=4.007, P\right.$ between 0.05 and 0.02 ). The number of recurrences of $E$. coli in those patients with abnormalities was not significantly higher than those without such abnormalities $\left(\chi^{2}=2.300, P\right.$ between 0.2 and 0.1 ). There was no significant difference in the time intervals of the recurrences between the patients with normal urinary tracts and those with abnormalities.

Rise and Fall of the Bacterial Counts.-Two patients, who were under close surveillance following recent attacks of urinary infection, demonstrated that the bacterial count may rise from the intermediate count to the high count overnight. One of the patients was in the wards and was having daily bacterial counts, the other, a medical student, was having twice-weekly counts. The in-patient with previous sterile cultures produced a count of 47,100 organisms per ml. of urine, which was followed next day by a count of more than 100,000 organisms per $\mathrm{ml}$. The other patient had a count of 51,000 organisms per ml., which also rose overnight to the significant level. Both had repeated confirmatory cultures over the next 24 hours and the strains of $E$. coli isolated were identical in the intermediate and the high counts. Similarly, identical isolates have been noted as the bacterial counts dropped after a response to treatment, particularly with sulphonamide therapy, where the bacterial counts tended to fall less abruptly than with other antibacterial drugs.

\section{Discussion}

The relapse rate of infections of the urinary tract has been little influenced by the use of the newer antimicrobials (Rhoads et al., 1952). Loopuyt (1946) found that $30 \%$ of his patients had relapses when followed up for one to three years ; Rhoads et al. (1952) considered that a relapse rate of up to $85 \%$ occurred over several months even in the absence of abnormalities of the urinary tract. Garrod et al. (1954) had a relapse rate in patients without abnormalities, over several months, of $40 \%$ in males and $18 \%$ in females. Kass (1955) stated that $90 \%$ of patients with chronic pyelonephritis may have recurrence of infection, and Jackson et al. (1957) found relapses in $50 \%$ of patients with acute pyelonephritis and in $75 \%$ of those with chronic pyelonephritis. In children Forsythe and Wallace (1958) noted recurrent infections in $30 \%$ of those without abnormalities ; Dunn, Hine, and MacGregor (1964) had similar results. These relapses occurred in patients who had shortterm therapeutic regimens with a wide variety of antimicrobial substances and suggest that long-term therapy would be more appropriate, particularly in the patient with a history of recurrence.

In this study, with the use of typing methods for the $E$. coli, 108 incidents have been recorded: $27.8 \%$ occurred within a month of the last infection, $42.6 \%$ within one to three months, $19.4 \%$ within three to six months, $5.6 \%$ in six to 12 months, and $4.6 \%$ after 12 months. Thus $90 \%$ of the recurrences had occurred up to six months since the last infection. Of these recurrences $84 \%$ of the strains were different from the strain isolated at the previous infection. Nearly $20 \%$ of these differ- 
ences were shown by a complete change in the typing markers and $68 \%$ demonstrated two or more changes in the markers.

There was no significant difference in the frequency of, or the time interval between, recurrences in the patients with abnormalities of the urinary tract and those without. Of course this comparison deals solely with recurrences in patients from whom $E$. coli was isolated, and so may not be a true reflection on the recurrence rate of the patients with abnormalities of the urinary tract. As has, been noted previously, the patients with abnormalities tend to have a higher frequency of infection by the non-Escherichia organisms (McGeachie, 1966).

The reproducibility of the typing methods was shown to be good by the correlation between the pretreatment samples from the patients, and this supplements the reliability of the isolates from the diagnostic plates previously described (McGeachie, $1965 \mathrm{a}, 1965 \mathrm{~b})$. The reproducibility was further confirmed by the identical strains in the two developing infections and also in the regressing infections.

These investigations on the recurrent infection of the urinary tract with $E$. coli would suggest that the recurrence is due to a strain which differs from the previous isolate in the majority of patients-that is, recurrence is reinfection rather than recrudescence in the majority of patients.

This poses a further question, that of therapeutic regimens, if the recurrent infection is due to another organism: Is there any justification for long-term therapy? Studies on renal biopsy may be of assistance in answering this. Though the difficulties arising from the focal and patchy nature of the disease make the routine use of renal biopsy of doubtful value in the diagnosis of pyelonephritis, several reports on renal biopsy in patients with pyelonephritis have appeared. In particular, those of Hutt and de Wardener (1961) and Brun and Raaschou (1961) are germane to this discussion. Hutt and de Wardener found evidence of persisting pathological changes, consistent with acute pyelonephritis, from 5 to 70 days after the onset of symptoms and after response to treatment. Brun and Raaschou commented on one patient, who had post-partum acute renal failure due to acute pyelonephritis, where histological changes of acute pyelonephritis persisted at three weeks and were still noted at a further biopsy four and a half years later ; however, they fail to state whether or not she had had further infections during this period. Nevertheless, both these reports suggest that the kidney may remain damaged long after the clinical and bacteriological cures may be pronounced.

Experimentally it has been shown that the damaged kidney is more readily infected than the normal ; Braude, Shapiro, and Siemienski (1955) and McCabe and Jackson (1960) used renal "massage" to render the kidney more susceptible. De Navasquez (1956) used staphylococci to produce a scarred kidney in which coliform bacilli subsequently produced infection, and Rocha, Guze, Freedman, and Beeson (1958) scarred the kidneys by electrocautery.

Thus it is likely that after an attack of pyelonephritis the kidney is more liable to reinfection for a period of time, as yet unknown for certainty, but probably to be measured in months. During this period of healing it seems advisable to supply antimicrobial "cover." The length of time for which this must be continued is at present being studied and will of necessity need further investigation before analysis of the results is complete. The evidence of the recurrent infections in this survey suggests that it is not unlikely that the minimum period of six months is required, since $90 \%$ of the incidents occurred within this time.

\section{Summary}

Forty-nine patients were investigated for 108 recurrent attacks of urinary infection with Escherichia coli. Thirty-eight patients without demonstrable abnormalities of the urinary tract had 69 incidents ; 11 patients with abnormalities of the urinary tract had 39 recurrences. No significant difference was noted in the frequency of recurrent attacks in these two groups.

Sixty-five pretreatment specimens, obtained from 23 patients, confirmed that the reproducibility of the typing markers was good. There was an agreement of $97 \%$ in both the colicine production and sensitivity, and with the serologically " smooth" strains there was agreement in $98.4 \%$.

Of the 108 recurrences $81(84.2 \%)$ were associated with different strains of $E$. coli, as shown by the typing markers.

Ninety per cent of the recurrences had occurred within six months of the previous infection. There was no significant difference in the time intervals of recurrence between the patients with and without abnormalities.

It is suggested that recurrent infections with $E$. coli are due in the majority of incidents to a reinfection rather than a recrudescence. The importance of this suggestion on the antibacterial management of the patient is discussed.

I wish to thank Dr. J. C. J. Ives for the facilities to complete this investigation. I am indebted to Dr. A. C. Kennedy for the clinical co-operation which made this investigation possible. I am grateful to Mr. J. Forrester for technical assistance.

\section{REFERENCES}

Braude, A. I., Shapiro, A. P., and Siemienski, J. (1955). 7. clin. Invest., 34, 1489.

Brun C., and Rasschou, F. (1961). In Ciba Foundation Symposium on Renal Biopsy, edited by G. E. W. Wolstenholme and M. P. Cameron, p. 245. Churchill, London.

De Navasquez, S. (1956). F. Path. Bact., 71, 27.

Dunn, P. M., Hine, L. C., and MacGregor, M. E. (1964). Brit. med. 7., 1,1081 .

Forsythe, W. I., and Wallace, I. R. (1958). Brit. 7. Urol., 30, 297.

Fredericq, P. (1965). Zbl. Bakt., I. Abt. Orig., 196, 142.

Garrod, L. P., Shooter, R. A., and Curwen, M. P. (1954). Brit. med. 7., 2, 1003 .

Hutt, M. S. R., and de Wardener, H. E. (1961). In Ciba Foundation Symposium on Renal Biopsy, edited by G. E. W. Wolstenholme and M. P. Cameron, p. 262. Churchill, London.

Jackson, G. G., Poirier, K. P., and Grieble, H. G. (1957). Ann. intern. Med., 47, 1165.

Kass, E. H. (1955). Amer. F. Med., 18, 764.

Kauffman, F. (1947). F. Immunol., 57, 71

Loopuyt, L. (1946). Acta med. scand., 125, 357.

McCabe, W. R., and Jackson, G. G. (1960). In Biology of Pyelonephritis, edited by E. L. Quinn and E. H. Kass, p. 39. Churchill, London.

McGeachie, J. (1965a). 7. clin. Path., 18, 428.

(1965b). Zbl. Bakt., I. Abt. Orig., 196, 377. (1965). Brit. F. Urol. In press.

- (1966). Brit. F. Urol. In press.

Rantz, L. A. (1962). Arch. intern. Med., 109, 37.

Rhoads, P. S., Billings, C. E., and O'Conor, V. J. (1952). F. Amer. med. Ass., 148, 165 .

Rocha, H., Guze, L. B., Freedman, L. R., and Beeson, P. B. (1958). Yale 7. Biol. Med., 30, 341

Ujváry, G. (1958). Zbl. Bakt., I. Abt. Orig., 170, 394.

Vahine, G. (1945). Acta path. microbiol. scand., Suppl. No. 62. 